\title{
EFFECT OF POTASSIUM ON RAM SPERMATOZOA STUDIED BY A FLOW DIALYSIS TECHNIQUE
}

\author{
H. M. DOTT* AND I. G. WHITE $\dagger$ \\ A.R.C. Unit of Reproductive Physiology and Biochemistry, \\ University of Cambridge
}

(Received 23rd Fuly 1963)

Summary. The continuous flow dialysis apparatus (CFDA) has been used to investigate the importance of potassium for the maintenance of the activity of ram spermatozoa.

Ram spermatozoa contain $136 \mathrm{mg} \mathrm{K} / 100 \mathrm{~g}$ and the seminal plasma $78 \mathrm{mg} \mathrm{K}+/ 100 \mathrm{~g}$. When semen is diluted one in three with a phosphate diluent, there is a rapid fall in the potassium concentration within the spermatozoa. Dialysis in the CFDA causes a further exponential fall unless potassium is included in the dialysis fluid. Unless the phosphate buffer used in the GFDA contains potassium ions, there is a sudden decrease in the impedance-change frequency (ICF) between 3 and $5 \mathrm{hr}$ from the start of dialysis. Washing or keeping unwashed spermatozoa for $2 \mathrm{hr}$ prior to dialysis does not alter this response or the time of dialysis at which it takes place.

Semen diluted one in three with fresh seminal plasma or with plasma obtained from stored semen gave the same response (fall in ICF). The decline in ICF due to the absence of potassium was less rapid when undiluted semen was used.

Semen washed with a bicarbonate buffer had a lower initial ICF than semen washed with phosphate, but the IGF declined more slowly, and in the absence of potassium there was no sudden drop in the ICF. Samples with potassium maintained a higher ICF than those without. The most marked potassium effect was obtained under aerobic conditions using a phosphate fluid containing fructose, lactate or acetate. Under anaerobic conditions the presence of potassium ions in the dialysis fluid had little or no effect on ICF.

\section{INTRODUCTION}

As already reported by White (1953a, b, c), the motility and glycolytic activity of ram spermatozoa are reduced by washing in a phosphate buffer containing sodium ions, chloride ions and fructose. He suggested that this effect was caused by a loss of potassium ions from the cells and showed that if potassium ions were included in the washing fluid the motility and glycolytic activity of the spermatozoa were unaffected by washing. Dott \& Walton (1960) also experimented

* Postal address: Animal Research Station, 307 Huntingdon Road, Cambridge.

† Present address: Department of Veterinary Physiology, University of Sydney, Sydney, Australia. 
with washed ram spermatozoa but they used a Ringer-bicarbonate solution which contained sodium, potassium, magnesium, chloride, carbonate, phosphate and sulphate ions. They observed that this solution caused a reduction of the impedance-change frequency (ICF) at each stage of the washing procedure, but the IGF then remained at a constant level for several hours. The results of their experiments suggested that, with Ringer-bicarbonate as a washing fluid, the ICF decreased chiefly owing to a decrease in endogenous respiration. Furthermore, Dott \& Walton (1960) found that after washing three times ram spermatozoa began to agglutinate and the agglutination involved more spermatozoa at each stage of the washing procedure. White (1953a, b, c) on the other hand observed no sign of agglutination in his washing experiments.

Apart from the different fluids used for washing there were other differences in the techniques used which might account for the discrepancy. The experiments described below were done to resolve these differences. The effect of dilution and dialysis on the potassium content of ram spermatozoa has also been studied.

\section{MATERIALS}

\section{SEMEN}

The semen for each experiment was collected with an artificial vagina from three Suffolk rams and pooled after the motility had been observed through a microscope equipped with a warm stage. Samples with poor motility were discarded.

\section{DILUENTS}

Two phosphate buffers were used in all experiments. One, the sodium phosphate buffer, contained: $0.032 \quad$ м- $\mathrm{NaH}_{2} \mathrm{PO}_{4} \cdot \mathrm{H}_{2} \mathrm{O} ; 0.048$ м- $\mathrm{Na}_{2} \mathrm{HPO}_{4} \cdot 12 \mathrm{H}_{2} \mathrm{O}$; $0.040 \mathrm{M}-\mathrm{NaCl} ; 0.022 \mathrm{M}$-fructose. The other, sodium-potassium phosphate buffer, contained: $0.032 \quad \mathrm{M}-\mathrm{NaH}_{2} \mathrm{PO}_{4} . \mathrm{H}_{2} \mathrm{O} ; 0.048 \quad \mathrm{M}_{-} \mathrm{Na}_{2} \mathrm{HPO}_{4} .12 \mathrm{H}_{2} \mathrm{O}$; $0.036 \mathrm{M}-\mathrm{NaCl} ; 0.004 \mathrm{M}-\mathrm{KCl} ; 0.022 \mathrm{M}$-fructose.

The concentrations of sodium chloride and potassium chloride were changed to $0.034 \mathrm{M}$ and $0.0064 \mathrm{M}$, respectively, for Experiments 3, 4, 5 and 6 so that the potassium ion concentration should be the same as in the bicarbonate buffer.

The 0.022 $\mathrm{m}$-fructose was omitted from half the samples in Experiment 2 and the control samples in Experiment 6 . In Experiment 6 it was replaced by $400 \mathrm{mg} / 100 \mathrm{ml}$ acetate, $20 \mathrm{mg} / 100 \mathrm{ml}$ fructose, $20 \mathrm{mg} / 100 \mathrm{ml}$ acetate or $20 \mathrm{mg} / 100 \mathrm{ml}$ lactate.

The following bicarbonate buffers were used in Experiment 3. (a) Sodium bicarbonate buffer, (b) sodium-potassium bicarbonate buffer. (a) Sodium bicarbonate buffer: 0.109 $\mathrm{M}-\mathrm{NaCl} ; 0.00105 \mathrm{M}-\mathrm{NaH}_{2} \mathrm{PO}_{4} ; 0.02205 \mathrm{M}-\mathrm{NaHCO}_{3}$; $0.022 \mathrm{~m}$-fructose. (b) Sodium-potassium bicarbonate buffer: $0.105 \mathrm{~m}-\mathrm{NaCl}$; $0.0042 \mathrm{~m}-\mathrm{KCl} ; 0.00105 \mathrm{~m}-\mathrm{KH}_{2} \mathrm{PO}_{4} ; 0.02205 \mathrm{~m}-\mathrm{NaHCO}_{3} ; 0.022 \mathrm{~m}$-fructose.

The same fluid was used for dilution, washing and dialysis except in Experiment 5 when some samples were diluted with seminal plasma. 
METHODS

The pooled semen was taken into the laboratory immediately after collection and part of it was diluted one in three in the appropriate fluid (i.e. $1 \mathrm{ml} \mathrm{semen}+$ $2 \mathrm{ml}$ fluid). Half of the diluted semen was kept at room temperature until the other half had been washed.

The washed spermatozoa were prepared by further diluting until a final dilution of one in ten was made, this was then subjected to a centrifugal force of about $225 \mathrm{~g}$ (1500 rev/min) for $10 \mathrm{~min}$. The sperm-free supernatant was removed reducing the volume by $85 \%$. This washing procedure, which was repeated four times, is similar to that used by White $(1953 \mathrm{~b}, \mathrm{c})$ and produces the same degree of washing. The final sperm density was the same as in the unwashed aliquot. At this stage one aliquot of washed and one of unwashed sperm suspension were put into the GFDA and readings of ICF taken every hour for $7 \mathrm{hr}$. A second aliquot was incubated in a tube at room temperature without further dilution; a third was incubated at $37^{\circ} \mathrm{C}$ without further dilution. The fourth and fifth aliquots were similarly incubated after dilution one in ten and the sixth and seventh after dilution one in one hundred. Samples of the aliquots incubated in tubes were taken every hour for estimates of motility. Motility was scored by the system of Emmens (1947).

\section{ESTIMATES OF POTASSIUM ION GONCENTRATION}

In experiments in which the amount of potassium ions removed from the semen was estimated, the potassium ion content of spermatozoa and the suspending fluid was estimated before and after varying periods of dialysis. The spermatozoa were separated from the suspending fluid by centrifuging $0.5 \mathrm{ml}$ of the suspension at about $300 \mathrm{~g}(2000 \mathrm{rev} / \mathrm{min})$ for $45 \mathrm{~min}$ in haematocrit tubes. The supernatant was removed with a fine Pasteur pipette and the supernatant and sperm diluted to an appropriate volume (10 to $25 \mathrm{ml}$ ) with distilled water. An EEL-flame photometer was used for the potassium analyses.

\section{STATISTICS}

Analyses of variance were done on the ICF and motility scores using the total score over the experimental period as unit observation and the pooled replicate interactions as error term. Further analyses including dialysis time were subsequently performed.

\section{EXPERIMENTAL}

ESTIMATES OF POTASSIUM ION CONCENTRATION

Analyses of six samples of fresh undiluted ram semen showed that the concentration of potassium ion in seminal plasma $(78 \mathrm{mg} / 100 \mathrm{~g}$ s.E. $\pm 3 \cdot 18)$ is about half that found in spermatozoa $(136 \mathrm{mg} / 100 \mathrm{~g}$ s.E. $\pm 7 \cdot 77)$. The potassium content of the spermatozoa falls by about one third on diluting the semen one in three with phosphate buffer and most of the rest of the potassium in spermatozoa is lost after 3 to $4 \mathrm{hr}$ dialysis although a little is retained even after dialysis for $6 \mathrm{hr}$ against a fluid containing no potassium ions (Text-fig. 2). 
The loss of potassium during dialysis can be reduced by including $0.006 \mathrm{M}-\mathrm{K}^{+}$ (i.e. $20 \mathrm{mg} / 100 \mathrm{~g}$ ) in the dialysis fluid (Table 1) but this does not prevent the rapid initial loss of potassium ions.

TABLE 1

EFFEGT OF DIALYSIS ON THE POTASSIUM CONTENT OF SPERMATOZOA

\begin{tabular}{|c|c|c|c|c|c|c|c|}
\hline \multirow{3}{*}{ Semen dilution } & \multirow{3}{*}{ Dialysis } & \multicolumn{6}{|c|}{ Potassium content of dialysis sac $(\mathrm{mg} / 100 \mathrm{~g})$} \\
\hline & & \multicolumn{3}{|c|}{ Spermatozoa } & \multicolumn{3}{|c|}{ Fluid } \\
\hline & & Rep. 1 & Rep. 2 & Mean & Rep. 1 & Rep. 2 & Mean \\
\hline Nil & $\begin{array}{l}0 \mathrm{hr} \\
6 \mathrm{hr} \text { in sodium phosphate } \\
\text { buffer } \\
6 \mathrm{hr} \text { in sodium-potassium } \\
\text { phosphate buffer }\end{array}$ & $\begin{array}{r}128 \\
12 \\
50\end{array}$ & $\begin{array}{r}104 \\
16 \\
42\end{array}$ & $\begin{array}{r}116 \\
14 \\
46\end{array}$ & $\begin{array}{r}83 \\
6 \\
43\end{array}$ & $\begin{array}{r}84 \\
8 \\
27\end{array}$ & $\begin{array}{r}84 \\
7 \\
35\end{array}$ \\
\hline $\begin{array}{l}1: 3 \text { in sodium phosphate } \\
\text { buffer }\end{array}$ & $\begin{array}{l}0 \mathrm{hr} \\
4 \mathrm{hr} \text { in sodium phosphate } \\
\text { buffer }\end{array}$ & $\begin{array}{l}74 \\
11\end{array}$ & $\begin{array}{l}60 \\
11\end{array}$ & $\begin{array}{l}67 \\
11\end{array}$ & $\begin{array}{r}38 \\
4\end{array}$ & $\begin{array}{r}23 \\
3\end{array}$ & $\begin{array}{r}31 \\
4\end{array}$ \\
\hline $\begin{array}{l}1: 3 \text { in sodium-potassium } \\
\text { phosphate buffer }\end{array}$ & $\begin{array}{l}0 \mathrm{hr} \\
4 \mathrm{hr} \text { in sodium-potassium } \\
\text { phosphate buffer }\end{array}$ & $\begin{array}{l}50 \\
59\end{array}$ & $\begin{array}{l}79 \\
54\end{array}$ & $\begin{array}{l}65 \\
57\end{array}$ & $\begin{array}{l}42 \\
33\end{array}$ & $\begin{array}{l}42 \\
24\end{array}$ & $\begin{array}{l}42 \\
29\end{array}$ \\
\hline
\end{tabular}

When undiluted semen is used in the CFDA the potassium concentration of the spermatozoa is well above those of the diluted samples throughout a $6-\mathrm{hr}$ period (Text-fig. 2).

\section{EXPERIMENTS IN THE CFDA}

Six experiments were done, and each experiment was repeated a number of times on different days with different samples of semen. Experiment 1 (three replicates) was designed to study the effect of potassium ions on aerobic and anaerobic fructolysis, and in Experiment 2 (six replicates) the effect of potassium ion on aerobic fructolysis and endogenous respiration was studied. In Experiment 3 (five replicates) the effects of phosphate and bicarbonate buffers were studied in the presence and absence of potassium ion. Experiment 4 (three replicates) was concerned with the effect of the subsequent response to dialysis of spermatozoa after storage at $20^{\circ} \mathrm{C}$. In Experiment 5 the effects of various diluents on the response of spermatozoa to dialysis without potassium ions in the dialysis fluid was investigated. Experiment 6 was concerned with the effect on ICF of supplying spermatozoa with fructose or lactate or acetate under aerobic conditions in the presence and absence of potassium. A $2 \times 3$ factorial design was used in each experiment.

\section{EXPERIMENT 1-COMPARISON OF ICF ASSOCIATED WITH AEROBIC AND ANAEROBIC FRUCTOLYSIS}

The dialysis fluids were sodium phosphate or sodium-potassium phosphate buffer, the gas was either nitrogen or oxygen and half the semen in each of the 
three replicates was washed. The results are presented in Text-fig. 1. To make it easier to follow, the curves of the mean values for the unwashed and washed are given separately though in each replicate they originate from the same pooled sample of semen. The washed spermatozoa had a lower ICF than the unwashed but the drop in ICF of spermatozoa deprived of potassium ions under aerobic conditions was of the same order and took place at the same time in washed and unwashed. Spermatozoa under anaerobic conditions had a lower IGF than those under aerobic conditions and the absence of potassium ion did not appear to affect them.

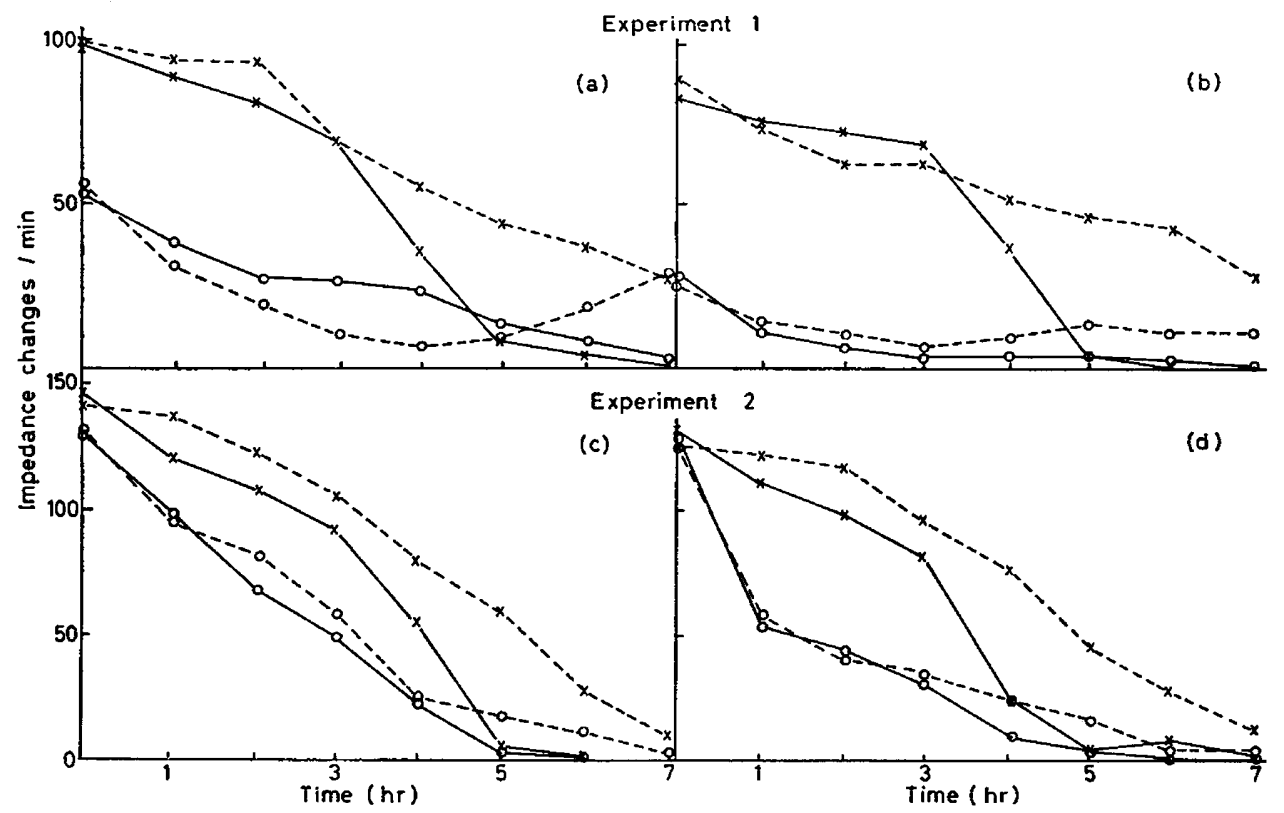

TEXT-FIG. 1. Experiment 1. ICF from aerobic or anaerobic fructolysis of ram spermatozoa in phosphate buffer. Each curve is the mean of three replicates. All curves are from subsamples of the same sample of semen. s.e. $=5.50$. (a) Unwashed; (b) washed; $\times$, aerobic; $O$, anaerobic; - - , sodium phosphate dialysis fluid; ---- , sodium potassium phosphate dialysis fluid.

Experiment 2. ICF from aerobic fructolysis or endogenous respiration of ram spermatozoa in phosphate buffer. Each curve is the mean of six replicates. All curves are from subsamples of the same sample of semen. S.E. $=4 \cdot 78$. (c) Unwashed; (d) washed; $\times$, fructose; $O$, without fructose; - sodium phosphate dialysis fluid; - - - , sodium potassium phosphate dialysis fluid.

\section{EXPERIMENT 2-COMPARISON OF ICF ASSOCIATED WITH AEROBIC FRUGTOLYSIS AND ENDOGENOUS RESPIRATION}

There were four fluids used in each of the six replicates comprising this experiment: namely sodium phosphate and sodium-potassium phosphate buffer (with fructose) and sodium phosphate and sodium-potassium phosphate without fructose. Half of the semen was washed. The results are presented in Text-fig. 1. The IGF of washed spermatozoa without fructose dropped very quickly at the beginning of the experiment but the spermatozoa remained active for the same length of time whether washed or not, although the presence 
of potassium ions seemed to prolong the time during which impedance changes could be detected. The four curves for sodium and sodium-potassium phosphate buffer confirm the results obtained in Experiment 1.

\section{EXPERIMENT 3-COMPARISON OF ICF WHEN PHOSPHATE AND BICARBONATE ARE USED AS BUFFERS}

All the dialysis fluids in these five replicates contained fructose and were gassed with either $100 \%$ oxygen (for phosphate) or $95 \%$ oxygen and $5 \%$ carbon dioxide (for bicarbonate). The effect of buffers, potassium and washing were tested and the results are illustrated in Text-fig. 2. Potassium resulted in

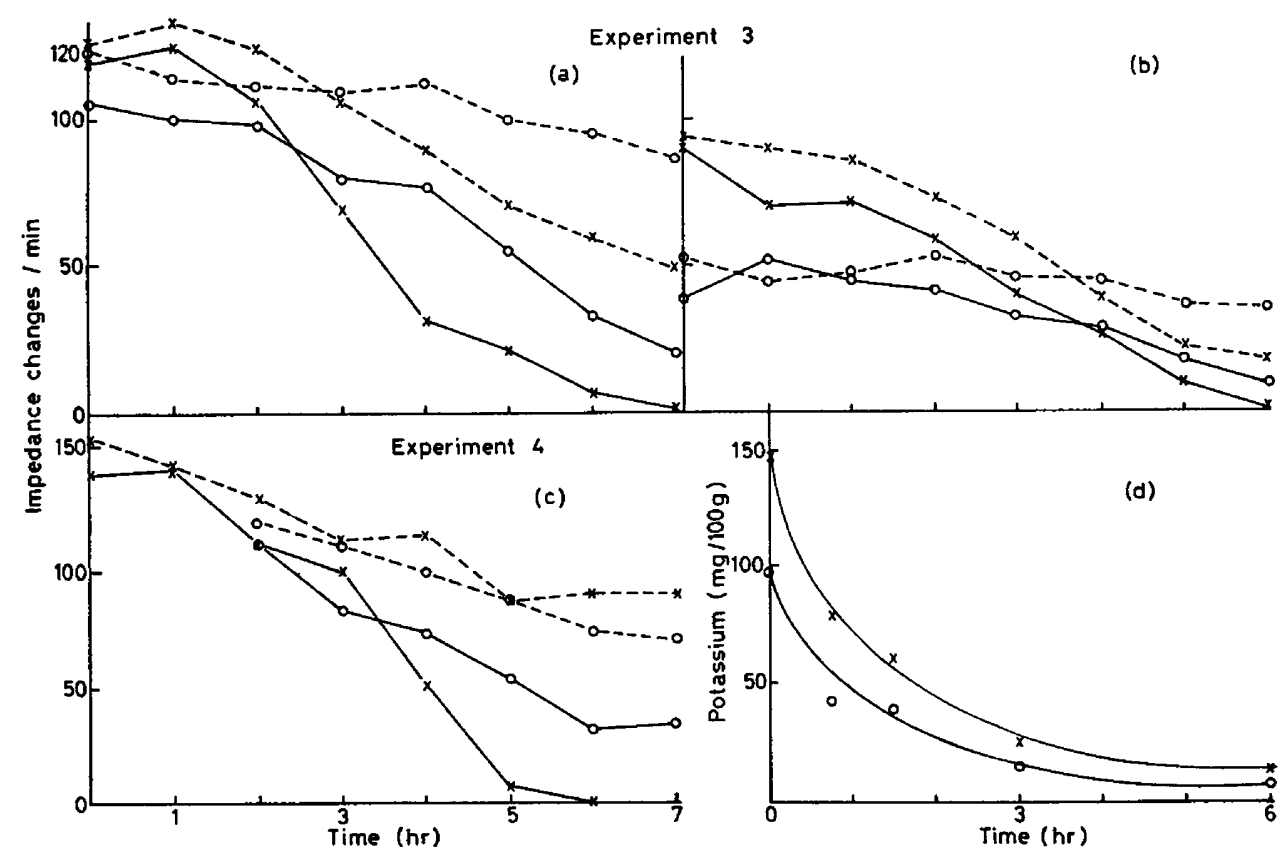

TEXT-FIG. 2. Experiment 3. IGF from aerobic fructolysis of ram spermatozoa in phosphate or bicarbonate buffer. Each curve is the mean of five replicates. All curves are from subsamples of the same sample of semen. s.e. $=5.88$. (a) Unwashed; (b) washed; sodium dialysis fluid; ---- , sodium potassium phosphate dialysis fluid; $\times$, phosphate dialysis fluid; 0 , bicarbonate dialysis fluid.

Experiment 4 . ICF of ram spermatozoa after storing at $20^{\circ} \mathrm{C}$ for $2 \mathrm{hr}$. Each curve is the mean of three replicates. All curves are subsamples of the same sample of semen. s.E. $=$ 8.43. (c) $\times$, fresh semen; $O$, stored semen; - - , sodium phosphate dialysis fluid; --- , sodium potassium phosphate dialysis fluid.

Graph (d) Rate of loss of potassium from ram spermatozoa on dialysis in the CFDA. Mean of two replicates. Concentration of potassium in semen after dialysis. $\times$, Undiluted semen; $O, 1 \mathrm{ml}$ semen in $2 \mathrm{ml}$ sodium phosphate buffer before dialysis.

a better maintenance of ICF when either a bicarbonate or a phosphate buffer was used as dialysis fluid. Washing with bicarbonate caused a bigger drop in ICF initially than washing in phosphate but after $7 \mathrm{hr}$ the spermatozoa in bicarbonate had a higher ICF ; the analysis of variance confirms both these points. With sodium phosphate buffer as dialysis fluid there was again a sharp drop in IGF but this took place at 5 to $7 \mathrm{hr}$ in some replicates instead of the more 
usual 3 to $4 \mathrm{hr}$. As a result the curve of the mean (Text-fig. 2) spuriously resembles the gentle declining curve for bicarbonate but the statistical analysis shows that there is a significant difference between them. It was observed that spermatozoa washed in the bicarbonate buffers agglutinated whereas those washed in phosphate buffers did not.

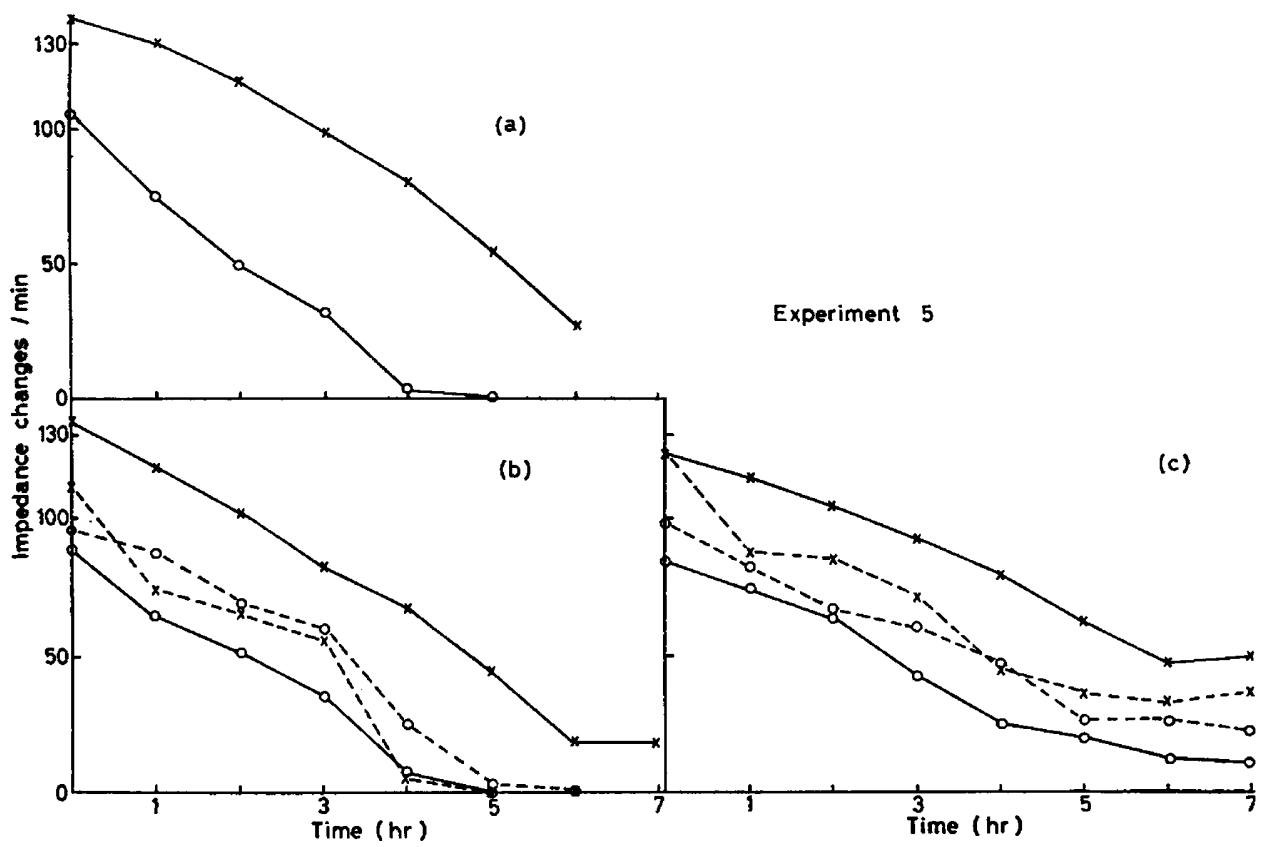

Text-Fig. 3. Experiment 5. Effect of dilution on the ICF of ram spermatozoa. (a) Sodium phosphate dialysis fluid. Each curve is the mean of seven replicates. s.e. $=5.38 . \times$, Undiluted; $O, 1 \mathrm{ml}$ semen in $3 \mathrm{ml}$ dialysis fluid. (b) Sodium phosphate dialysis fluid. Each curve is the mean of three replicates. s.E. $=17.58 . \times \frac{1}{x}$, Undiluted; $x----x$, diluted with dialysis fluid; $0-0$, diluted with fresh seminal plasma; $0---O$, diluted with seminal plasma from stored semen. (c) Sodium potassium phosphate dialysis fluid. Each curve is the mean of three replicates. s.E. = 17.58. Symbols as in (b).

\section{EXPERIMENT 4-EFFECT OF STORAGE}

In the first three experiments dialysis did not begin until about $2 \mathrm{hr}$ after the first dilution because half the semen had to be washed. In subsequent experiments we planned to omit the washing procedure as there was little evidence that it affected the reaction of spermatozoa to depletion of potassium. Before taking this step an experiment was done to compare the response of fresh diluted spermatozoa with spermatozoa which had been diluted $2 \mathrm{hr}$ before being put in the dialysis apparatus. Phosphate buffers gassed with oxygen were used. The fresh semen had a higher ICF at the beginning of dialysis (Text-fig. 2); but after $5 \mathrm{hr}$ dialysis, semen without potassium ions in the dialysis fluid had a very low ICF whereas semen with potassium ions had a higher ICF. The sudden drop in ICF among samples with no potassium ions took place about $4 \mathrm{hr}$ after the beginning of dialysis in the fresh semen as it had done in the stored in all previous experiments and in the stored controls in this group. 


\section{EXPERIMENT 5-EFFECT OF DILUTION}

This experiment was done to investigate first the effect of dilution with sodium phosphate buffer and then of dilution with seminal plasma. There were seven replicates in which dilution was done with the buffer; the diluted semen had zero ICF after $4 \mathrm{hr}$ dialysis and the undiluted semen had a higher initial ICF and continued until the experiment ended after $6 \mathrm{hr}$ (Text-fig. 3).

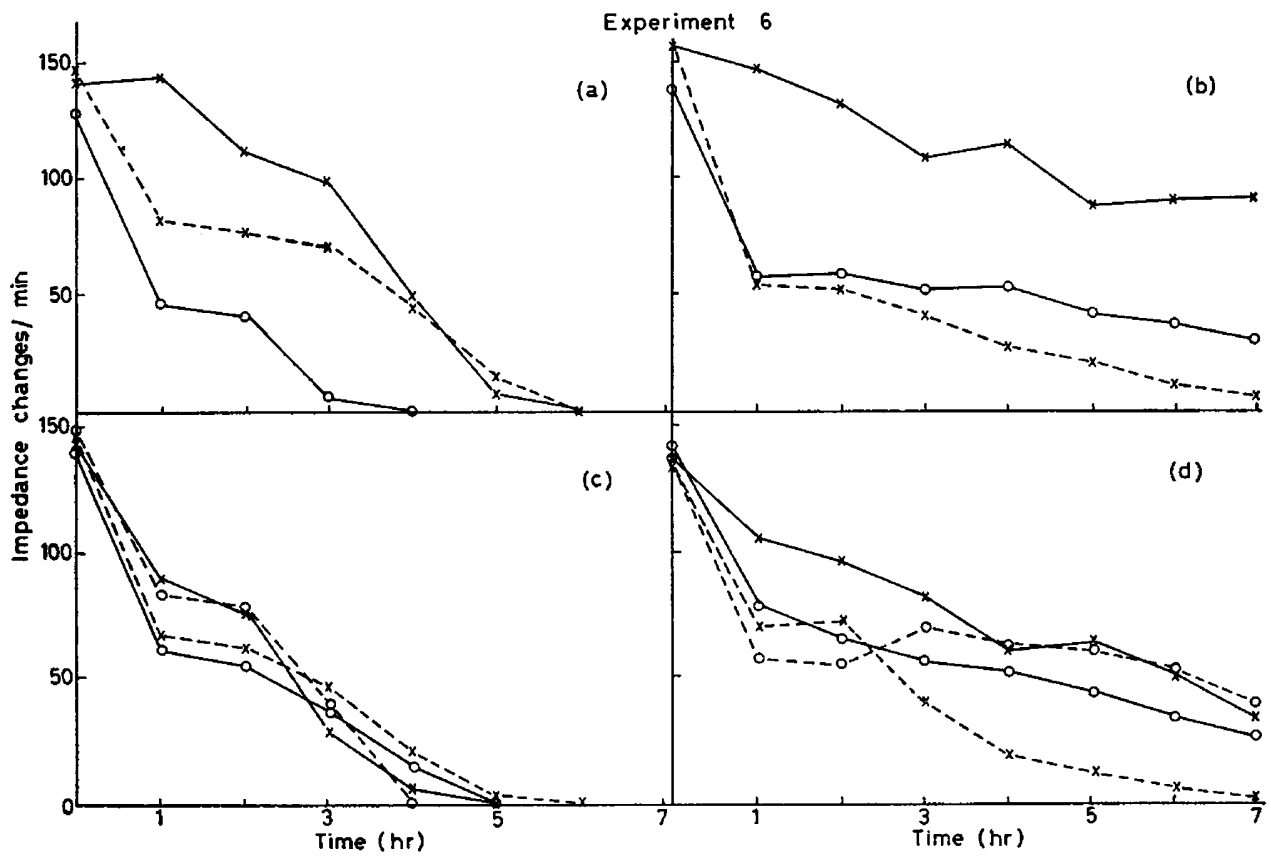

Text-FIG. 4. Experiment 6 . ICF from aerobic fructolysis, endogenous respiration, oxidation of lactate or acetate by ram spermatozoa. Each curve is the mean of three replicates. All curves are subsamples of the same sample of semen. (a) Sodium phosphate dialysis fluid; (b) sodium potassium phosphate dialysis fluid. (a) and (b) s.E. $=7 \cdot 18 ; 400 \mathrm{mg}$ substrate/100 ml dialysis fluid. (c) Sodium phosphate dialysis fluid; (d) sodium potassium phosphate dialysis fluid. (c) and (d) s.e. $=0.93 ; 20 \mathrm{mg}$ substrate $/ 100 \mathrm{ml}$ dialysis fluid. $\times \frac{}{0}$, Fructose in dialysis fluid; $x---x$, no substrate in dialysis fluid; 0 , acetate in dialysis fluid; $0---0$, lactate in dialysis fluid.

There were three replicates in which dilution was done either with buffer, fresh seminal plasma or seminal plasma from semen kept at $4^{\circ} \mathrm{C}$ overnight. Dilution, by itself, caused a lower ICF but there was no significant difference between diluents. After $7 \mathrm{hr}$ the undiluted aliquots without potassium ions had not such a high ICF as the undiluted aliquots with potassium ions but there was no rapid decline at 3 to $4 \mathrm{hr}$ (Text-fig. 3 ).

\section{EXPERIMENT 6-THE FUNCTION OF POTASSIUM IONS}

In Experiments 1 and 2 it was shown that in the absence of potassium ions spermatozoa became inactive if both oxygen and fructose were available. If on the other hand either fructose or oxygen was not supplied the spermatozoa appeared to be less affected by the absence of potassium ions. To find out more 
about this, first three replicates were done in which acetate or fructose were present at a concentration of $400 \mathrm{mg} / 100 \mathrm{ml}$ (Text-fig. 4). In the absence of potassium ions acetate at this concentration seemed to depress the ICF very quickly. When potassium ions were present the aliquots with acetate had a higher ICF than those with no substrate in the dialysis fluid but a lower ICF than aliquots with fructose in the dialysis fluid.

It seemed possible that acetate at this concentration was exerting some direct effect on the spermatozoa which might obscure the potassium ion effect, therefore three more replicates were done in which the dialysis fluids were basically sodium and sodium-potassium phosphate buffer without fructose. Acetate, lactate or fructose were added at a concentration of $20 \mathrm{mg} / 100 \mathrm{ml}$ where appropriate. The gas phase was oxygen. All the spermatozoa with added substrate behaved alike (Text-fig. 4), i.e. unless potassium ions were present the ICF of samples given a substrate fell below that of the sample without added substrate after $5 \mathrm{hr}$ but when potassium ions were present fructose, lactate and acetate maintained good activity over the $7 \mathrm{hr}$ of the experiment.

\section{EFFECT OF POTASSIUM ON MOTILITY}

Generally speaking motility studies confirmed the results obtained in the CFDA and those reported by White (1953a, b) previously. A beneficial effect of $0.004 \mathrm{M}$ or $0.006 \mathrm{M}$-potassium was seen when ram semen was diluted one in 100 with either phosphate or bicarbonate diluents. Unless 0.004 M-potassium was present the spermatozoa were usually immotile after 3 or $4 \mathrm{hr}$ at $37^{\circ} \mathrm{C}$. In contrast to the experiments in the CFDA this effect manifested itself whether or not fructose, lactate or acetate were added to the diluent, which is not surprising since the semen itself contains fructose and the ratio of spermatozoa to fructose would be unaltered by dilution. At a dilution of one in ten or one in three there was no significant effect of potassium on the motility of the unwashed spermatozoa.

If, however, the spermatozoa were washed to remove potassium a beneficial effect of adding $0.004 \mathrm{M}$ or $0.006 \mathrm{~m}$-potassium could be demonstrated. This became apparent after incubating for 3 to $4 \mathrm{hr}$ in phosphate buffer at a dilution of one in ten but not one in three, and not in bicarbonate buffer.

\section{DISCUSSION}

The primary object of the experiments described in this paper was to reconcile the conflicting observations of White (1953a, b, c) and Dott \& Walton (1960). White found washing ram spermatozoa had no effect on their motility provided potassium was included in the washing fluid, on the other hand Dott \& Walton found the ICF of ram spermatozoa was reduced by washing even in the presence of potassium.

As a preliminary to the investigations measurements were made on the potassium content of spermatozoa before and after dilution and dialysis with a phosphate buffer. A dilution of one in three reduced the potassium concentration from $116 \mathrm{mg} / 100 \mathrm{~g}$ to $66 \mathrm{mg} / 100 \mathrm{~g}$ (Table I). Dialysis further reduced the potassium concentration but a low concentration of potassium $(20 \mathrm{mg} / 100 \mathrm{~g})$ 
in dialysis fluid maintained the concentration in the spermatozoa at about $60 \mathrm{mg} / 100 \mathrm{~g}$. The immediate drop in potassium concentration in the spermatozoa when semen is diluted one in three is not reflected in an immediate drop in motility or ICF (Text-fig. 1). But dialysis for 4 or $5 \mathrm{hr}$ with a sodium phosphate buffer causes a further reduction in the concentration of potassium in the spermatozoa (Text-fig. 2) which is accompanied by a drop in IGF (Text-fig. 1).

After $6 \mathrm{hr}$ dialysis with sodium phosphate buffer, spermatozoa in undiluted semen have a higher ICF (Text-fig. 3 ) and a higher concentration of potassium (Text-fig. 2) than spermatozoa in semen diluted one in three with sodium phosphate buffer before dialysis commences. Even when the diluting fluid is seminal plasma (Experiment 5, Text-fig. 3) the ICF is reduced to zero at about $5 \mathrm{hr}$ when potassium is not present in the dialysis fluid. In fact it is only diluted semen which reveals the importance of potassium in the metabolism of ram spermatozoa, and this is confirmed in the dilution experiments using motility as a criterion. These showed that the greater the degree of dilution the greater the need for potassium in the diluting fluid to preserve the motility of the spermatozoa.

From the above it can be concluded that potassium is associated with ram spermatozoa in at least three ways, (1) a loose association which is ended by dilution with a phosphate buffer and probably with seminal plasma, (2) some potassium is held more firmly so that a low concentration of potassium in the suspending fluid is enough to enable the spermatozoa to retain it, and (3) potassium which is not lost when semen is diluted with sodium phosphate buffer and is not released after $6 \mathrm{hr}$ dialysis with the same buffer. Unfortunately the significance of the results obtained in the dilution experiment did not become apparent until the experimental part of this work had been completed and no measurements were made of the rate of loss of potassium from spermatozoa in semen diluted with a bicarbonate buffer. In view of the similar results obtained with undiluted semen and semen diluted with a bicarbonate buffer in the CFDA (Experiment 5, Text-fig. 3 and Experiment 3, Text-fig. 2) it is possible that only the loosely associated potassium is lost when semen is diluted and dialysed with a bicarbonate buffer.

The washing method and Ringer used by Dott \& Walton (1960) had already been thoroughly investigated in the CFDA therefore it was decided to use the washing procedure and buffer described by White (1953a) in the present work. In the experiment to compare phosphate and bicarbonate (Experiment 3 ) this meant simplifying the solution used by Dott \& Walton (1960) by omitting magnesium ions and sulphate ions, and the final theoretical dilution of seminal plasma by the washing procedure was about one in 10,000 compared with one in 1459 (Dott \& Walton, 1960). Despite the increase in the degree of dilution of the seminal plasma and in the rate of dilution the effect on the initial ICF of washing with bicarbonate buffer was much less than expected (Experiment 3, Text-fig. 2). It may be that the magnesium and sulphate ions in the solution used by Dott \& Walton (1960) were responsible in part for the deleterious effect of washing. The ICF of spermatozoa when the bicarbonate buffer was used as a dialysis fluid remained fairly constant over $7 \mathrm{hr}$ dialysis except for the unwashed spermatozoa in sodium bicarbonate and the ICF fell 
gradually throughout the $7 \mathrm{hr}$ dialysis and not suddenly between 3 and $5 \mathrm{hr}$ as was the case in sodium phosphate buffer. The results obtained with the bicarbonate buffer as dialysis fluid (excluding unwashed spermatozoa in sodium bicarbonate buffer) are in agreement with Dott \& Walton (1960).

Thus, as a result of controlled experiments it can be said that the difference between the observations by White (1953a, b, c) and Dott \& Walton (1960) were primarily due to the use of phosphate as a buffer by White and bicarbonate by Dott \& Walton. This is shown most simply and convincingly by the observation that washing aliquots of the same sample of semen in the same way produced agglutination of the spermatozoa when bicarbonate was used and not when phosphate was used as buffer.

The final part of this work was an attempt to relate, to some metabolic process in ram spermatozoa, the potassium released during dialysis with phosphate buffer, i.e. potassium 'held more firmly' (as just defined in (2) above).

Ram spermatozoa are capable of aerobic and anaerobic fructolysis (Mann, 1946; Mann \& Lutwak-Mann, 1948) and Dott (1958) found the ICF of ram spermatozoa is dependent on the gas phase and supply of substrate. There are at least three pathways by which ram spermatozoa can obtain energy for motility (Mann, 1954; Hartree \& Mann, 1961); (1) anaerobic breakdown of fructose to lactic acid, (2) aerobic oxidation of lactic acid by the Krebs cycle, and (3) aerobic breakdown of fatty acids formed from endogenous plasmalogen.

Dott (1958) showed that ram spermatozoa display the highest ICF under aerobic conditions with fructose in the dialysis fluid, i.e. when it is possible for them to use all three pathways at once. Previously it has been shown that washing with calcium-free Krebs-Ringer bicarbonate affects the ICF when endogenous respiration is the source of energy (Dott \& Walton, 1960) and after washing with sodium phosphate buffer that lactic acid production was decreased but oxygen uptake was unaffected (White, 1953c).

Now it appears that ICF associated with both anaerobic fructolysis (Experiment 1, Text-fig. 1) and endogenous respiration (Experiment 2, Text-fig. 1) is unaffected by washing ram spermatozoa in sodium phosphate buffer. The evidence from the experiments described in this paper (Experiments 1,2 and 6 , Text-figs. 1 and 4), suggests that the critical effect of potassium depletion is on the ability of ram spermatozoa to produce or make use of energy from the oxidation of exogenous substrate over the Krebs cycle.

\section{ACKNOWLEDGMENT}

We would like to thank Mr P. English of Veterinary School of Medicine, Cambridge, for his help with the potassium analyses.

\section{REFERENCES}

Dotт, H. M. (1958) Species differences in the metabolism of epididymal spermatozoa. Stud. Fertil. 10, 73.

Dotr, H. M. \& Walton, A. (1960) Effects of dilution and washing on ram spermatozoa studied by the flow dialysis technique. $\mathbf{7}$. Reprod. Fertil. $1,350$.

Emmens, G. W. (1947) The motility and viability of rabbit spermatozoa at different hydrogen-ion concentrations. F. Physiol. 106, 471. 
Hartree, E. F. \& Mann, T. (1961) Phospholipids in ram semen. Metabolism of plasmalogen and fatty acids. Biochem. 7. 80, 464.

Mann, T. (1946) Studies on the metabolism of semen. 3. Fructose as a normal constituent of seminal plasma. Site of formation and function of fructose in semen. Biochem. 7. 40, 481.

ManN, T. (1954) The biochemistry of semen. Methuen, London.

Mann, T. \& Lutwak-ManN, C. (1948) Studies on the metabolism of semen. 4. Aerobic and anaerobic utilization of fructose by spermatozoa and seminal vesicles. Biochem. $7.43,266$.

WhIte, I. G. (1953a) The effect of washing on the motility and metabolism of ram, bull and rabbit spermatozoa. 7. exp. Biol. 30, 200.

Whrte, I. G. (1953b) The effect of potassium on the washing and dilution of mammalian spermatozoa. Aust. F. exp. Biol. med. Sci. 31, 193.

White, I. G. (1953c) Metabolic studies of washed and diluted ram and bull spermatozoa. Aust. $\mathcal{F}$. biol. Sci. 6, 706.

White, I. G. (1957) Metabolism of glycerol and similar compounds by bull spermatozoa. Amer. $\mathcal{J}$. Physiol. 189, 307. 